\title{
SJOGREN'S SYNDROME AND CRYOGLOBULINEMIC VASCULITIS PRESENTING WITH REFRACTORY ACUTE PULMONARY EDEMA
}

Viviane Queiroz de Oliveira Maia ${ }^{1, \star}$, Iane Tamara Dondé1, Gizelle Gouvea Rezende ${ }^{1}$, Luciana Akita', Viviane Alves Costa, Danielly Dantas Pimentel', Gustavo Roberto Lourenço', Juliana de Jesus Boscolo', Maria Alice Sperto Ferreira Baptista', Ricardo Acayaba de Toledo', Taisa Morete da Silva ${ }^{1}$

1.Faculdade de Medicina de São José do Rio Preto, São José do Rio Preto (SP), Brazil.

*Corresponding author: viviane_vi82@yahoo.com.br

\section{BACKGROUND}

Mixed cryoglobulinemia develops in up to a third of patients with Sjögren's syndrome, but the manifestations of vasculitis are present only in a small number of cases. The clinical and laboratory characteristics of mixed cryoglobulinemia and Sjögren's syndrome also overlap.

\section{CASE REPORT}

Female patient, 44 years old, with a history of xerophthalmia and xerostomia, in an outpatient investigation of Sjögren's syndrome, admitted to the hospital due to dyspnea, auscultation with bilateral pulmonary rales, blood pressure $180 \times 80 \mathrm{mmHg}$, establishing a diagnosis of acute pulmonary edema. On clinical examination, there was presence of hyperchromic macules in the lower limbs and the patient reported feeling of paresthesias. During the complementary investigation, it was evidenced: anemia, lymphopenia and urine I showing active urinary sediment, with the presence of leukocyturia, hematuria, hemoglobinuria and proteinuria, and a proteinuria/creatinuria ratio of 1.03, antinuclear antibody (ANA) reagent 1/160 cytoplasmic pattern, non-reactive anti-DNA and anti-Sm, reactive anti-Ro (> 240), complement system C3 (75) and C4 (1). In view of the hypothesis of Sjögren's syndrome, laboratory alterations, the presence of cicatricial skin lesions suggestive of purpura in the lower limbs (Fig. 1), the hypothesis of cryoglobulinemia was suggested. Cryoglobulin dosage: $212 \mu \mathrm{g} / \mathrm{mL}$ (up to $80 \mathrm{mcg}$ ), immunoglobulin G-polyclonal and M-kappa monoclonal present (mixed cryoglobulinemia). Renal biopsy showed glomeruli with increased volume, lobulation, mesangial expansion; cell proliferation; PAS-positive hyaline deposition in glomerular capillaries and duplication of the basement membrane of the capillary loops (Fig. 2). In addition, small vessels with signs of vasculitis. In this context, pulse therapy with methylprednisolone 500 mg for 3 days was

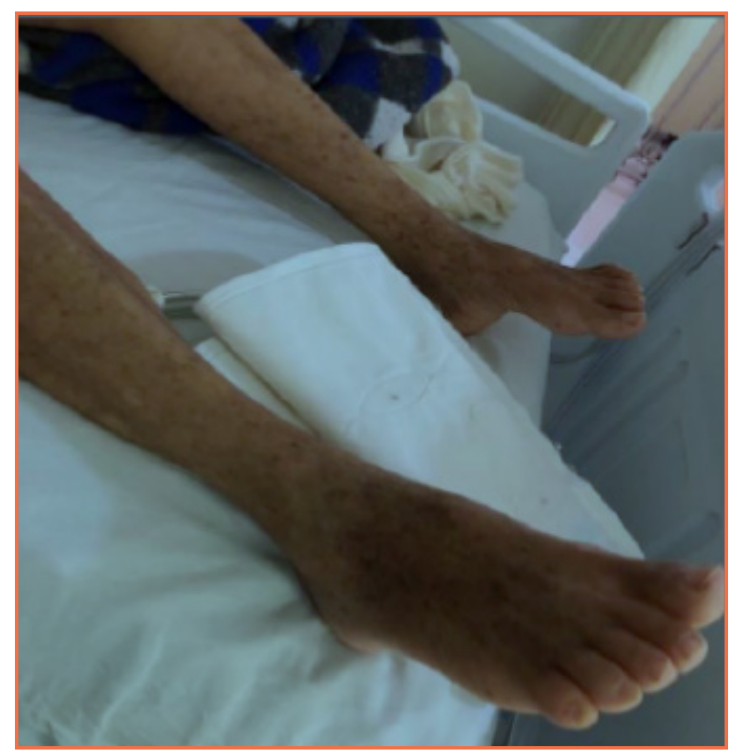

Figure 1. Lower limb hyperpigmentation repeated episodes of purple in a patient with mixed cryoglobulinemia. 
indicated. The patient evolved during hospitalization with an infectious condition, recurrent acute pulmonary edema requiring nipride, high-dose diuretic therapy and nephrological support. She spent approximately 14 days in intensive care. After improvement of the infectious condition and blood pressure controls, pulse therapy with cyclophosphamide $0.6 \mathrm{mg} / \mathrm{m}^{2}$ monthly, for 6 months, with maintenance corticosteroid therapy of $50 \mathrm{mg}$ daily was indicated. Subsequently, as maintenance therapy, the patient finds azathioprine with significant improvement in glomerulonephritis and adequate pressure controls.

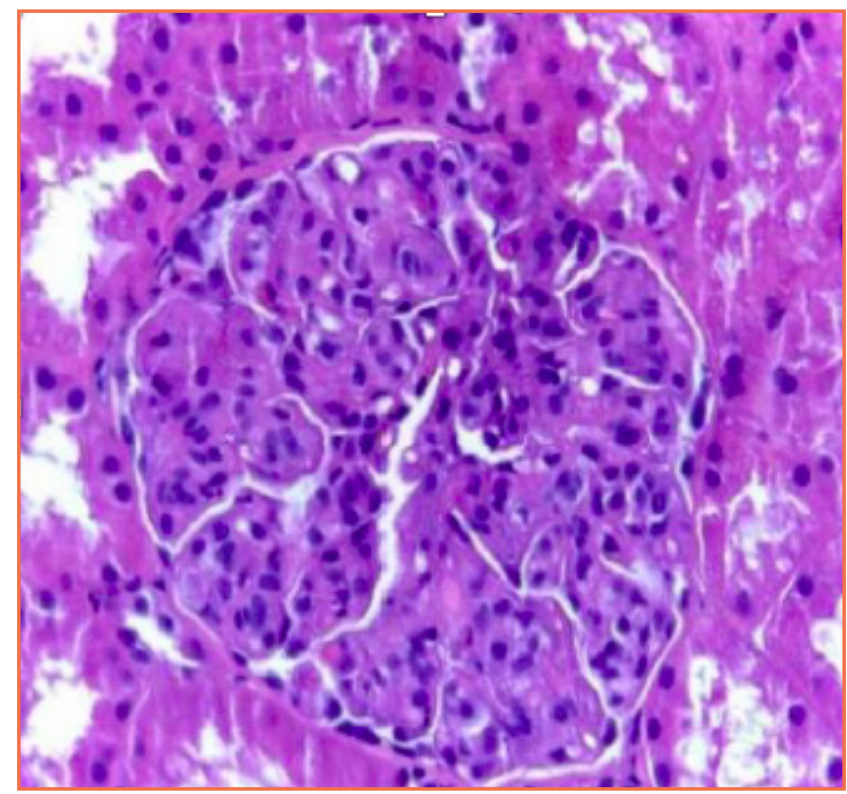

Figure 2. Hematoxylin-eosin $400 \times$ : glomeruli with lobulation, proliferation of mesangial, inflammatory and endothelial cells.

\section{CONCLUSION}

It is important to remember this association between Sjögren's syndrome and cryoglobulinemia as a differential diagnosis in the context of an emergency unit, since the presentation of the condition was initially with acute hypertensive edema. 